\title{
Thymic Mucosa-Associated Lymphoid Tissue Lymphoma
}

National Cancer Institute

\section{Source}

National Cancer Institute. Thymic Mucosa-Associated Lymphoid Tissue Lymphoma. NCI

Thesaurus. Code C45380.

\begin{abstract}
A low-grade extranodal marginal zone lymphoma of mucosa-associated lymphoid tissue that affects the thymus. It is characterized by the presence of centrocyte-like or monocytoid lymphocytes that surround reactive lymphoid follicles. There is infiltration of the thymic epithelium by lymphocytes and formation of lymphoepithelial lesions. It is associated with the presence of autoimmune disease, most frequently Sjogren syndrome. Patients are usually asymptomatic and the tumor is detected incidentally as a mediastinal mass on chest x-ray. A minority of patients present with dyspnea, hemoptysis, and chest pain. The prognosis is excellent.
\end{abstract}

